\title{
Tecendo a Rede de Proteção às Crianças e Adolescentes em Situação de Risco para a Violência do Município de Curitiba/PR ${ }^{1}$
}

\author{
Cleide Lavoratti ${ }^{2}$
}

- Enviado em 28/11/2015

- Aprovado em 30/05/2016

\section{RESUMO}

A Rede de Proteção às Crianças e Adolescentes em Situação de Risco para a Violência do município de Curitiba/PR. é um programa intersetorial criado para articular ações de enfrentamento à violência no âmbito das políticas públicas de educação, saúde e assistência social, que mantem parceria com diversas instituições não governamentais atuantes na proteção da população infanto-juvenil. A pesquisa analisou o desenho institucional dessa Rede e as tensões que se faziam presentes nesta interação que congrega intersetorialidade, interdisciplinaridade e uma metodologia de rede de políticas públicas, tanto no que se refere aos conflitos dos agentes entre si, como dos agentes as instituições envolvidas no enfrentamento à violência. A rede é uma estratégia operacional de uma nova forma de gestão das políticas de enfrentamento à violência contra crianças e adolescentes. Ela deveria propiciar a articulação de ações intersetoriais, a partir da concepção de política preconizada pelo Estatuto da Criança e do Adolescente, que cria um Sistema de Garantias dos Direitos. No entanto, por sua natureza de informalidade, flexibilidade, agilidade e descentralidade, opera com dificuldades no setor público, dada a permanência de uma cultura organizacional das políticas, marcadas historicamente pela hierarquia, setorização, centralização do poder de decisões. A pesquisa aponta os principais desafios para o desenvolvimento de ações públicas intersetoriais e conclui que a relação de interdependência entre agentes e instituições participantes da Rede de Proteção, ao mesmo tempo que potencializa as ações de enfrentamento à violência, gera constante tensão entre as instituições e os profissionais que atuam na área.

Palavras-chave: Crianças e adolescentes. Violência intrafamiliar. Rede de proteção.

\section{INTRODUÇÃO}

Este trabalho, fruto das pesquisas realizadas durante o Doutorado em Sociologia cursado na Universidade Federal do Paraná (Brasil), busca compreender como se tecem as articulações entre os agentes no setor público; como se criam e se fortalecem os vínculos necessários para uma atuação em rede de políticas públicas; como os agentes percebem e avaliam

\footnotetext{
${ }^{1}$ Tese de doutorado em Sociologia defendida em 15 de abril de 2013 no Programa de Pós-graduação da UFPR, realizado sob a orientação da Professora Doutora Maria Tarcisa Silva Bega. Versão integral disponível em http://www.humanas.ufpr.br/portal/pgsocio/files/2013/09/TESE-CLEIDE-LAVORATTI-2013.pdf. Pesquisa financiada pela Fundação Araucária.
}

${ }^{2}$ Doutora em Sociologia pela UFPR. E-mail: lavoratti@yahoo.com.br 
esta nova cultura organizacional; e, por fim, buscou avaliar se a política pública incorporou de fato a concepção de rede como estratégia operacional e organizacional de suas ações, através da análise de uma experiência concreta de política pública de enfrentamento da violência intrafamiliar contra crianças e adolescentes: a "Rede de Proteção às Crianças e Adolescentes em Situação de Risco para a Violência" do município de Curitiba/PR (Brasil).

Nosso objeto de estudo, portanto, é um programa intersetorial criado em 2000 para articular as ações das políticas públicas de educação, saúde e assistência social e estruturar a notificação e atendimento dos casos de violência contra crianças e adolescentes. A "Rede de Proteção" é organizada a partir de uma coordenação municipal intersetorial, nove coordenações situadas nas grandes regionais de Curitiba e cerca de 100 redes-locais distribuídas nos bairros da cidade. Mantem parceria com diversas instituições governamentais (delegacias, Ministério Público, Juizados, etc.) e não governamentais (hospitais, Ordem dos Advogados do Brasil, instituições de acolhimento institucional) que atendem vítimas de violência.

Este programa tem sido referência constante em publicações do Ministério da Saúde que tratam do atendimento às vítimas de violência, e, devido a sua permanência ao longo da última década em diferentes gestões municipais, despertou nossa atenção para que pudéssemos conhecer a forma como foi criado, os agentes que contribuíram com sua implementação, as diretrizes que fundamentam o trabalho em rede, além dos avanços e dificuldades que encontra em operar ações intersetoriais no âmbito das políticas públicas.

A hipótese central do nosso trabalho é que a rede (pensada em termos ideais) é uma estratégia operacional de uma nova forma de gestão das políticas públicas para o enfrentamento da complexidade da problemática da violência intrafamiliar contra crianças e adolescentes. Ela deveria articular as ações municipais de enfrentamento à violência a partir da concepção de política de atendimento preconizada pelo ECA. No entanto, por sua natureza de informalidade, flexibilidade, agilidade e descentralidade, opera com dificuldades no setor público dada a permanência da cultura organizacional das políticas sociais marcadas historicamente pela hierarquia, setorização e centralização do poder de decisões. Por outro lado, acreditávamos que muitos agentes continuavam a operar as ações públicas sem incorporar as novas concepções criadas pela legislação social nas últimas décadas, o que contribuía para a manutenção de práticas tradicionais (repressivas e de controle social) no atendimento realizado às vítimas e às famílias. 
A partir desses pressupostos, e buscando compreender como se configurava as políticas de enfrentamento à violência intrafamiliar contra crianças e adolescentes do município de Curitiba, Paraná (BR) elaboramos as questões norteadoras do trabalho:

- Como se dava a relação de interdependência entre as instituições que participam da "Rede de Proteção às Crianças e Adolescentes em Situação de Risco para a Violência"?

- Como se relacionam as instituições e os agentes nesta experiência intersetorial de enfrentamento à violência?

- Quais eram as tensões e conflitos que se faziam presentes nesta interação específica que congrega intersetorialidade, interdisciplinaridade e uma metodologia de rede de políticas públicas?

Para responder estas e demais questões que surgiram durante a pesquisa, lançamos mão de diversos instrumentais para a coleta de dados empíricos. Inicialmente, realizamos entrevistas semiestruturadas com os profissionais que iniciaram o Programa em Curitiba para conhecer os elementos históricos que contribuíram com a estruturação deste trabalho no município. Entrevistamos dois médicos, uma odontóloga, uma socióloga e uma assistente social, vinculados à instituições públicas e privadas que atuavam direta ou indiretamente com a temática em questão. Também realizamos um levantamento documental que nos propiciou compreender de que forma a violência contra a população infanto-juvenil veio sendo publicizada no município, demandando uma intervenção governamental.

Além dos precursores do Programa (os quais não estão vinculados atualmente a ele), entrevistamos os coordenadores municipais da "Rede de Proteção" para verificar as mudanças ocorridas desde sua criação e as configurações atuais do enfrentamento à violência contra crianças e adolescentes no município. Também buscamos através de um questionário obter a participação de agentes que se encontram na coordenação da "Rede de Proteção" em outros níveis (regional e local). Foram aplicados 324 questionários (dos quais retornaram 115) e realizadas 27 entrevistas com os iniciantes, integrantes e coordenadores municipais, regionais e locais da "Rede". A intenção foi compreender as percepções que agentes que se localizam em diferentes níveis de atuação tinham acerca da "Rede de Proteção", dos avanços do trabalho intersetorial (participação, interatividade, comunicação, hierarquia), e dos desafios de conviver com crianças e adolescentes vítimas de violência, dentro de uma proposta de política pública que adotou a perspectiva do trabalho em rede. 
O critério de escolha dos coordenadores locais, regionais e municipais se deu pelo fato de que os participantes da base não teriam condições de responder sobre a estrutura e funcionamento da "Rede de Proteção". Dessa forma, os participantes que se encontravam em melhor posição para opinar sobre o desenho institucional do programa eram os coordenadores municipais, regionais e locais.

Como instrumento de coleta de dados utilizamos ainda a observação nas reuniões da "Rede de Proteção" e um diário de campo para registrar elementos que permitissem analisar o cotidiano das relações que se estabeleciam entre os agentes do Programa. O diário permitiu um olhar para além dos discursos estruturados proferidos pelos agentes no momento da entrevista ou do preenchimento do formulário. Presenciamos vários momentos de tensão, ambiguidade e conflito, que não seria possível captar se utilizássemos apenas os dados coletados pelos instrumentos tradicionais.

Esse artigo é composto por alguns tópicos que buscam discutir aspectos mais significativos da pesquisa de doutorado, a partir dos depoimentos de agentes públicos do município de Curitiba/PR: como se iniciou este trabalho no município de Curitiba (PR) e como se deu o processo de oficialização do Programa pelo poder executivo municipal. Além disso, qual é a avaliação dos agentes sobre o funcionamento da "Rede de Proteção às Crianças e Adolescentes em Situação de Risco para a Violência”, sua relação com as entidades parceiras, além das tensões e conflitos que permeiam esta forma de interação social que vincula os profissionais pelo sofrimento e pelo convívio com a dor do outro.

Por fim busca compreender como os agentes se sentem na "Rede de Proteção" e de que forma a violência tem impactado na vida dos profissionais que convivem diariamente com as mais diversas situações de violação dos direitos humanos de crianças e adolescentes.

\section{CONTEXTO A PESQUiSa: A REDE DE PROTEÇÃO À CRIANÇA E AO ADOLESCENTE EM SITUAÇÃO DE RISCO PARA A VIOLÊNCIA DO MUNICÍPIO DE CURITIBA - PR.}

Os anos 80 e 90 foram marcados por conquistas jurídicas e mobilizações nacionais e internacionais importantes na área da infância e da juventude no Brasil: a nova Constituição Federal 
brasileira (1988); a aprovação da Declaração Internacional dos Direitos da Criança e do Adolescente (1989); o ECA e a construção de um Sistema de Garantias de Direitos das Crianças e Adolescentes (1990); o I Congresso Mundial contra a Exploração Sexual Comercial de Crianças (1996) realizado em Estocolmo, que aprovou diretrizes para o enfrentamento da violência sexual, entendendo-a como uma grave violação de direitos humanos, que deveria ser combatida por Planos Nacionais; dentre outros acontecimentos históricos que provocaram mudanças na concepção do atendimento à população infanto-juvenil, que, segundo este aparato legal, deve primar pela participação da sociedade civil e pela articulação das políticas públicas em rede intersetoriais.

Compreender de que forma este movimento global de luta pela garantia dos direitos humanos de crianças e adolescentes repercutiu na realidade local do município de Curitiba é o objetivo deste trabalho, que busca reconstruir, a partir do relato dos profissionais que vivenciaram este processo, os elementos históricos que contribuíram para a criação de uma experiência intersetorial de enfrentamento à violência contra crianças e adolescentes.

A "Rede de Proteção à Criança e ao Adolescente em Situação de Risco" foi criada no município de Curitiba inicialmente para dar visibilidade à problemática da violência contra crianças e adolescentes, como uma das expressões da violência urbana nas principais capitais brasileiras. “(...) desse trabalho de sistematizar os dados então nasceu a Rede, quer dizer, a Rede, ela não nasceu, ela veio como decorrência de uma necessidade de informações sobre a violência (...) mas ela foi se desenvolvendo a partir disso (...)” (ASSISTENTE SOCIAL 1).

(...) a Rede surgiu na necessidade de notificar, então a primeira ideia era conhecer o problema. Bom, ai foi toda uma discussão, como notificar? Quem notifica? A saúde notifica, mas onde que a criança fica mais tempo? Fica na escola. O que dizem os educadores? Então a escola notifica. A creche tem que notificar! O hospital notifica. E aquilo foi ampliando. (SOCIÓLOGA).

No primeiro Manual de Atendimento da "Rede" (posteriormente chamado de Protocolo) elaborado em 2002, nos chamou a atenção a constante menção a outros órgãos como coparticipes do processo de criação e mobilização da "Rede", como os conselhos tutelares, a Pastoral da Criança, alguns hospitais privados, além de universidades públicas e privadas e o Juizado da infância e da Juventude.

Participaram da formulação, implantação e acompanhamento dessa ação integrada: as Secretarias Municipais de Saúde, Educação Meio ambiente, a Fundação de Ação Social, o Instituto de Pesquisa e Planejamento Urbano de Curitiba, o Instituto Municipal de Administração Pública, os Conselhos Tutelares e a Sociedade Paranaense de Pediatria. (OLIVEIRA, et al, 2004, p. 144). 
Além disso, observamos que o Manual traz as atribuições dos agentes envolvidos com a notificação e com o atendimento às vítimas de violência que atuavam nos diversos órgãos, inclusive nos conselhos tutelares. Também normatiza fluxos de atendimento e encaminhamento dos casos de violência contra crianças e adolescentes.

No começo se falava que a rede era autônoma, cada um decidia. Chegaram a mudar o nome da Rede de Proteção no banner, chegaram a usar outros conceitos. Daí assim, quando a gente fez o nosso Protocolo, a gente deu uma normatizada nos trabalhos, porque foi necessário. (MÉDICA 2 - COORDENAÇÃO MUNICIPAL).

(...) os fluxos são um avanço porque o profissional pega o Protocolo, mesmo que ele esteja chegando naquele serviço e não deu tempo do chefe (...). Se ele pegar o Protocolo ele vai saber o que ele tem que fazer, porque o fluxo está bem detalhado e ele sabe por onde ele vai caminhar. Então eu acho que os fluxos foram um avanço sim. O Protocolo é um avanço, o Protocolo como um todo é um avanço. (PSICÓLOGA - COORDENAÇÃO MUNICIPAL).

Como nos aponta um dos agentes que atuou desde o início da "Rede de Proteção", o Protocolo foi um importante instrumento da gestão deste programa intersetorial, elaborado através de muita negociação e pactuação com as entidades participantes, visando definir as atribuições e competências das secretarias envolvidas e agilizar a proteção às vítimas. Ao mesmo tempo em que dava segurança para os agentes que atuavam em conjunto no enfrentamento à violência contra a população infanto-juvenil.

Com relação às competências das instituições, das secretarias envolvidas, isso a gente foi construindo aos poucos, em conjunto. Então depois passou bem a estipular pelo Protocolo, o que cada um faz, o que todo mundo faz, o que cada um faz que só ele faz, e o que você pode esperar do outro. (ODONTÓLOGA).

A criação e a consolidação da experiência local da "Rede de Proteção" pode ser entendida como uma grande mobilização social, da qual participaram agentes de diversas áreas que estavam inseridos (embora às vezes sem consciência disso) num movimento global, nacional e internacional, de mudança de olhar e de sensibilidade social em relação aos direitos humanos de crianças e adolescentes. Movimento iniciado no final do século XX, e que se consolidou legalmente no Brasil com aprovação do artigo 227 da Constituição Federal de 1988 e do Estatuto da Criança e do Adolescente em 1990. 
(...) eu me sinto, assim, privilegiada, porque tanto da questão do Estatuto da Criança e do Adolescente, de você participar da Assembleia Constituinte e você ver as propostas sendo contempladas na Constituição, depois você vê o Estatuto da Criança e do Adolescente criado, e depois você vê também a Rede, que começa um pouquinho, uma coisa pequena e que hoje é um Programa adotado pela Prefeitura. Então assim, você se sente protagonista disso, é bem bacana sabe, bem legal, é uma coisa de conjunto que a gente participou, e que ficou bem gratificada (...) (ASSISTENTE SOCIAL 02).

A "Rede de Proteção" foi criada em Curitiba no ano de 2000 com o objetivo principal de "Contribuir para a redução da violência contra a criança e o adolescente em Curitiba, especialmente no que se refere à violência doméstica" (CURITIBA, Prefeitura Municipal, 2002, p.17).

Inicialmente foi criado um instrumento de notificação obrigatória (NO) para padronizar as denúncias de violência contra crianças e adolescentes no município por parte das instituições públicas e privadas que atendiam este público.

E ai a gente foi construindo, primeiro a ficha, a gente foi construindo toda a composição da ficha de notificação, o fluxo dessa ficha e a montagem de uma Rede. Uma Rede que tinha como objetivo notificar e intervir o mais precocemente possível na questão violência. Então ai se constituiu a Rede, e nasceu dessa forma. Ela começou realmente a funcionar como Rede em 2000. (SOCIÓLOGA).

O trabalho inicial de implantação da "Rede de Proteção" e da Notificação Obrigatória não se deu de forma fácil, nem isenta de conflito e dificuldades advindas tanto das barreiras impostas pelas "linguagens" próprias de cada profissão, como dos receios dos agentes sobre o quanto se envolver, e como se envolver com uma questão ainda tão pouco debatida e conhecida na realidade brasileira nesta época.

Como era uma atividade pioneira da qual não se tinha conhecimento de como fazer, como organizar o trabalho, isso gerava certa insegurança frente ao novo, mas para o grupo mobilizador da "Rede" isso se colocava como um desafio.

(...) como a gente não tinha conhecimento de algo parecido no Brasil, nós começamos em cima exatamente do pouco de literatura que a gente tinha de fora do país - mas era muito pouca - alguma coisa francesa, alguma coisa americana, ai muito mais como serviço instituído e não como Rede. Em cima daquilo que vinha na nossa cabeça, em cima do desafio do cotidiano. (SOCIÓLOGA). 
E os desafios não foram poucos no início: a partir do pouco retorno dos profissionais da saúde e da educação em relação ao preenchimento das fichas de notificação na regional do Portão, outras estratégias foram testadas pelo grupo que coordenava a iniciativa.

Curitiba na época tinha oito distritos sanitários, e o distrito Portão acatou a possibilidade da gente estar começando a implantação por lá, tinha uma enfermeira que era supervisora também, uma pessoa muito sensível a esse problema, ela acolheu essa proposta e também as outras secretarias porque é uma proposta intersetorial. (ODONTÓLOGA).

Uma das iniciativas utilizadas foi identificar agentes já sensibilizados com a problemática para que estes atuassem como mediadores com suas instituições de origem, buscando "quebrar" as resistências à proposta realizada.

(...) começamos a perceber também a resistência das pessoas, principalmente de algumas categorias profissionais, o médico principalmente, mas também alguns profissionais da educação, no sentido de retaliação, de represália por parte do agressor (...) a gente tinha que se organizar pra dar uma proposta que não só notificasse, mas também se organizasse para o acompanhamento dos casos notificados e também para prevenção. (ODONTÓLOGA).

Outra estratégia foi colocar os agentes que atuavam nas diferentes políticas públicas, numa relação face-a-face, propiciando a criação de vínculos e o processo de enredamento a partir de capacitações intersetoriais.

(...) colocamos todo mundo junto, saúde, educação, ação social, chamamos a pastoral da criança, igreja, quem tivesse, quem a gente identificasse naquela regional que tivesse um perfil pra isso. A gente chamou para sentar junto e começamos tudo novamente, e a notificação passou a ser um detalhe, o que a gente queria era possibilitar o trabalho integrado entre todos, tanto na notificação quanto no acompanhamento dos casos (ODONTÓLOGA).

A percepção de que a intersetorialidade seria um dos pilares do trabalho a ser implementado contribuiu para orientar as estratégias adotadas pelo grupo coordenador das atividades, tendo em vista que a intersetorialidade é compreendida como: “(...) a articulação de conhecimentos, experiências, para que se realize, planeje, avalie as ações de interesse público, buscando uma sinergia em situações complexas" (INOJOZA, 1999, p.116). No entanto, como observamos pelos depoimentos sobre as dificuldades encontradas pelos agentes para trabalharem 
com uma atividade considerada inovadora, mas sobre a qual além de não possuírem o controle total, também se evidenciavam as diferenças profissionais e institucionais, na forma de compreensão do fenômeno da violência e da percepção sobre os possíveis encaminhamentos a serem realizados, a intersetorialidade se colocava como um elemento de tensão que retirava os agentes da "zona de conforto" na qual estavam acostumados a trabalhar. Se o convívio com agentes com a mesma formação profissional e a mesma linguagem técnica já era um desafio, devido às características individuais de cada agente, que influenciavam na forma como conduziam suas práticas nos espaços sócio-ocupacionais, que dirá conviver com agentes com formações heterogêneas, linguagem e formas de compreensão diversificadas? "Foi um processo muito grande de aprendizagem, de troca de uma coisa muito rica, porque, a saúde, ela vai com sua experiência e até no seu vocabulário, a educação. chega com outro vocabulário, com outro olhar, e assim a ação social também..." (ODONTÓLOGA).

Mesmo com essas dificuldades iniciais, o grupo mobilizador acreditava que, frente à complexidade das situações de violência notificadas, era necessário enfrentar a cultura organizacional das políticas sociais, marcadas historicamente pela setorização e isolamento institucional.

A gente percebia que a pessoa que trabalhava na Unidade de Saúde não conhecia o diretor da escola ou a pessoa da creche, a gente via que eles não sabiam nem o nome, nem um telefone, não é? Então isso foi uma estratégia que a gente só fazia se fosse assim. (...) a gente estruturou as coordenações regionais também, essa foi uma estratégia importante, que da mesma forma que tinha uma coordenação municipal intersetorial, quando a gente chegava no distrito para implantar, a gente já formava, antes de implantar, a gente já constituía a coordenação regional naquela região (...) então em cada rede local, tinham lá os coordenadores, os participantes, então era tudo nominado, tudo muito certinho (...) (ODONTÓLOGA).

Para tanto, foram estruturadas "redes-locais" descentralizadas em todos os bairros da cidade, tendo como referência para cada "rede" o território de abrangência da Unidade Básica de Saúde. As "redes" eram formadas também por articuladores das escolas municipais, dos serviços de assistência social e pelos conselhos tutelares ${ }^{3}$.

O trabalho de mapeamento dos equipamentos públicos de cada regional foi ajudando a dar concretude ao suporte institucional já implantado, que a "Rede" necessitaria para o seu

\footnotetext{
${ }^{3}$ Curitiba possui nove Conselhos Tutelares.
} 
funcionamento. Conhecer as escolas, as unidades de saúde, os serviços assistenciais de cada localidade contribuíram para a organização das "redes-locais".

O que a gente fez foi chamar de Redes Locais a área de abrangência de cada unidade básica, porque a unidade de saúde é muito importante na rede, (...). (SOCIÓLOGA).

As "redes-locais" se tornaram a "alma" da "Rede de Proteção", tendo em vista que se trata do espaço onde a violência se expressa de diferentes maneiras e é também onde os encaminhamentos serão discutidos a priori. As "Redes" se reúnem mensalmente e discutem coletivamente os casos de violência contra crianças e adolescentes da sua região de abrangência. Elas ajudaram a romper com o tradicional fatiamento das demandas da população por política setorial, a partir do momento em que a exigência de uma atuação em conjunto ampliava o olhar sobre a complexidade das demandas sociais e sobre as intervenções que dariam conta de resolver, ou ao menos amenizar as questões postas pela população.

Atualmente são mais de 100 "redes-locais" no município de Curitiba. No início de 2011, quando realizamos a pesquisa de campo, eram 97 "redes". No entanto, dada a dinâmica específica da "Rede de Proteção", há uma constante variação no número de "redes-locais", haja vista a necessidade de disponibilidade pessoal para realizar um trabalho articulado intersetorialmente. "Então eu vejo que onde nós nos aproximamos realmente com um ideal, com destino de rede, são nas redes locais. Eu vejo que rede local... eu sinto, ela tem maior mobilidade (...)” (PEDAGOGA $1)$.

Além da articulação dos órgãos governamentais, era necessário também integrar parceiros da sociedade civil organizada, conselhos tutelares, hospitais e demais serviço privados que atendiam a população infanto-juvenil.

Em 2000 a "Rede de Proteção" já contava com "redes-locais" em toda a cidade, tendo apoio de 8 Comissões Regionais que faziam a mediação, o fortalecimento e acompanhavam o trabalho nas "redes-locais" e tinham como função:

- dar continuidade e unidade às redes locais de proteção;

- constituir-se em referência para as equipes regionais em relação a problemas, dificuldades e encaminhamentos;

- estabelecer a ligação entre as redes locais e a coordenação municipal da rede de proteção;

- garantir o fluxo da notificação obrigatória;

- envolver a comunidade local como parceira;

- divulgar o trabalho da rede e ampliar o espectro de instituições participantes. (OLIVEIRA et al, 2004, p. 148 grifos nossos). 
A articulação prosseguia buscando estruturar além dos serviços de notificação, o atendimento às vítimas de violência sexual.

Depois que a gente implantou nas regionais, a gente começou a implantar nos Hospitais, também Hospital para Hospital. Nessa época o Pequeno Príncipe, o Evangélico e o Hospital das Clínicas já eram hospitais de referência para a violência sexual. Se tornaram referência sexual dentro do Programa Mulher de Verdade, que eu coordenava também. Então, além da rede, eu tinha o Mulher de Verdade (risos) (...) o Pequeno Príncipe ficou [com atendimento] até doze anos, violência sexual, e os outros de doze em diante, o Evangélico e o HC [Hospital das Clínicas]. Indiretamente eles incorporaram a Rede também, em 2002. (ODONTOLOGA).

A coordenação municipal da "Rede de Proteção", inicialmente constituída por representantes de várias instituições do município de Curitiba, tinha por competência:

- viabilizar a articulação de todos os serviços e programas envolvidos, respeitando as diferenças institucionais;

- contribuir para a mudança de paradigma quanto à metodologia de trabalho, fortalecendo o princípio de rede e rompendo a tradição de ações isoladas e setorizadas;

- manter um sistema de capacitação permanente;

- estabelecer fluxo e sistema de processamento de informações, alimentando um banco de dados com análises periódicas para a definição de prioridades;

- dar unidade às redes regionais, identificando problemas e estabelecendo propostas de encaminhamento;

- constituir-se em referência para as equipes regionais em relação a problemas, dificuldades, encaminhamentos para os casos de maior complexidade, ente outros. (OLIVEIRA, 2004, p. 148-149).

Esta Coordenação, formada inicialmente pelas Secretarias Municipais de Saúde, Educação, Assistência Social, IPPUC, Sociedade Paranaense de Pediatria, dentre outras instituições, sustentava as ações da "rede de proteção" tecnicamente e politicamente. Tecnicamente, pelo fato de produzirem estatísticas através do Banco de Dados de Notificação e de sistematizarem constantemente a experiência de construção do trabalho, dando concretude às ações e explicando os problemas enfrentados pela "Rede" e os avanços obtidos. Além disso, a "Rede" contava ainda com o "saber médico" como suporte às ações propostas. Politicamente, porque conseguiram sensibilizar e mobilizar muitos parceiros públicos e privados que pactuavam com as deliberações do grupo, que a cada dia se fortalecia mais pela adesão de novos agentes e de novas instituições. 
Atualmente com a oficialização da "Rede de Proteção" como programa municipal ocorreram algumas mudanças. A Coordenação Municipal continua colegiada mas, agora formada apenas por representantes das secretarias de educação, saúde e assistência social, com centralidade administrativa e coordenação geral na Secretaria Municipal da Saúde, que é quem define as pautas e cronogramas das reuniões com as coordenações regionais (mensais), e com os parceiros (trimestrais), e gerencia toda a organização do trabalho intersetorial. Também constituem a Rede nove Coordenações Regionais com membros das três principais áreas envolvidas (Saúde, Educação e Assistência Social) e por cerca de 100 "redes-locais intersetoriais" distribuídas pelo município de Curitiba que congregam os serviços de educação (escolas municipais), as unidades de saúde (US) e os centros regionais de Assistência Social $\left(\mathrm{CRAS}^{4}\right.$ e CREAS $\left.{ }^{5}\right)$. A referência territorial das "redeslocais" é a área de abrangência da unidade de saúde .

A Coordenação Municipal tem o papel de "Articular instituições governamentais e não governamentais para a efetivação de ações integradas e intersetoriais no âmbito municipal, a fim de prevenir a violência, principalmente a doméstica e a sexual, e proteger a criança e o adolescente em situação de risco para a violência.” (CURITIBA, Prefeitura Municipal, 2008, p. 39), além de ser responsável pela gestão política e executiva do Programa. Estabelece as principais parcerias da "Rede" com outras instituições públicas e privadas (hospitais, delegacias, Juizado, etc.) e media os conflitos mais graves que aparecem no trabalho da "Rede".

As Coordenações Regionais são referências para as equipes das redes-locais, em termos de capacitação, articulação e fortalecimento do Programa nos bairros, fazendo a mediação de comunicação entre a Coordenação Municipal e as redes-locais. São formadas por agentes que atuam nos equipamentos regionais das Secretarias de Saúde (distrito sanitário), de Educação (Núcleos Regionais) e da Fundação de Assistência Social (CRAS e CREAS). Localizam-se nas administrações regionais de Curitiba ${ }^{6}$.

Os agentes das "Redes-locais" são os que atendem diretamente as crianças e adolescentes em situação de vulnerabilidade e são responsáveis pela identificação, notificação e acompanhamento dos casos de violência em sua área de abrangência. Atuam nas escolas municipais

\footnotetext{
${ }^{4}$ Centro Regional de Assistência Social.

${ }^{5}$ Centro Regional Especializado de Assistência Social.

${ }^{6}$ Curitiba foi dividida em 9 administrações regionais, também conhecidas como sub-prefeituras. "As Administrações Regionais permitem uma atuação intersetorial alinhada às diretrizes traçadas pelo município, mantendo capacidade gestora para solucionar demandas e propor avanços voltados à melhoria da qualidade de vida da população contando ainda, com a sua efetiva participação." (INSTITUTO MUNICIPAL DE ADMINISTRAÇÃO E PLANEJAMENTO, 2012).
} 
de ensino fundamental e nos centros de educação infantil, nas unidades de saúde e nas instituições de assistência social. Reúnem-se mensalmente para estudar os casos notificados e realizar o monitoramento dos mesmos. Muitas redes-locais contam ainda com a participação (em alguns momentos) de conselheiros tutelares e representantes de instituições não governamentais.

\section{OS SUJEITOS DA PESQUISA}

Como mencionamos nas considerações iniciais, devido à amplitude da atuação da "Rede de Proteção" e o número de envolvidos com o trabalho, aplicamos questionários para os agentes que atuam na coordenação dos três níveis da "Rede" (municipal, regional e local). Inicialmente buscamos no questionário informações gerais que identificassem o público da pesquisa.

A maioria dos agentes que atuam na coordenação da "Rede de Proteção" é do sexo feminino (mais de 90\%), sendo rara a presença masculina mesmo nas atividades de capacitação ou nas reuniões com os parceiros, nas quais participamos como observadores. Isso nos leva a conclusão de que a mulher culturalmente assume o papel de cuidadora também na vida profissional, quer seja escolhendo profissões que trabalhem com doentes, com idoso ou com crianças e adolescentes (médicas, enfermeiras, professoras, assistentes sociais, etc.) ou mesmo sendo designadas para setores, dentro das políticas públicas, que atuam diretamente com o público que precisa de "cuidados".

Pudemos observar o perfil dos agentes atuantes na "Rede de Proteção" tratam-se majoritariamente de mulheres maduras, com mais de 40 anos, com alta escolaridade, com formação nas áreas de Pedagogia, Serviço Social e Enfermagem, e que atuam na "Rede" há um tempo considerável, que permite o conhecimento da estrutura e funcionamento da "Rede de Proteção". Por outro lado, são agentes públicos que estão há bastante tempo exercendo uma atividade que os coloca constantemente em contato com situações de violência, sofrimento, dor e perdas, e que exigem deles respostas profissionais que tragam o alívio para as pessoas com as quais trabalham.

Além das informações sobre o perfil dos coordenadores, o questionário também foi organizado através de algumas variáveis, escolhidas a partir da revisão teórica sobre redes de políticas públicas, para conhecer a forma como os agentes da "Rede de Proteção" percebem sua estrutura e funcionamento. São elas: 
1 - Se os objetivos da "Rede de Proteção" são compartilhados com todas as instituições e agentes envolvidos;

2 - O fluxo de informação e comunicação no Programa;

3 - A percepção da existência de hierarquia na "Rede de Proteção";

4 - A avaliação se a forma de organização da "Rede de Proteção" (objetivos, atividades, coordenações, fluxos, etc.) favorece o enfrentamento da violência intrafamiliar contra crianças e adolescentes;

5 - A avaliação dos coordenadores se a "Rede de Proteção" consegue atender e acompanhar todos os casos de violência intrafamiliar notificados;

Segundo os documentos oficiais da "Rede de Proteção", seu objetivo geral é de "Contribuir para a redução da violência contra a criança e o adolescente em Curitiba, especialmente no que se refere a violência doméstica." (CURITIBA, Prefeitura Municipal, 2011; CURITIBA, Prefeitura Municipal, 2008).

Os coordenadores foram unânimes em afirmar nas respostas que os objetivos e valores da "Rede de Proteção" são compartilhados entre as instituições que participam deste trabalho.

Em relação ao fluxo de informações e comunicação na "Rede de Proteção", os coordenadores municipais afirmam nos questionários que é muito intenso e frequente (100\%). Mas, nas entrevistas, acabam revelando alguns aspectos importantes que interferem no atendimento realizado.

\footnotetext{
Às vezes esse fluxo acontece mais facilmente, e outras vezes esse fluxo também não acontece assim com tanta rapidez. Depende do caso, depende de que tipo de atendimento que vai ser necessário. Às vezes, na saúde, a gente encontra alguns gargalos, tenta minimizar o tempo para que o atendimento aconteça o mais breve possível, mas nem sempre ele é rápido, às vezes demora. (PEDAGOGA 2 - COORDENAÇÃO MUNICIPAL ) .
}

Segundo os depoimentos e pelas observações realizadas nas reuniões da "Rede" , identificamos que a linguagem muitas vezes aparece mais como um empecilho que como facilitadora ao processo de comunicação. “(...) o trabalho em rede demanda toda uma adequação, não só do saber, mas como, do que se fala, e nunca a gente tinha percebido que as falas são tão diferentes.” (MÉDICA 2 - COORDENAÇÃO MUNICIPAL).

E esse é um dos grandes elementos de tensão no grupo. Nem sempre um termo tem o mesmo significado para agentes de áreas diferentes. Nem sempre a mensagem emitida por uma coordenação chega à outra com o mesmo sentido. Talvez porque os coordenadores regionais e os 
coordenadores locais, apesar de concordarem que o fluxo de informações/comunicação é muito intenso e frequente, o fazem em menor percentual $(66,7 \%$ e $58,2 \%$, respectivamente) que os coordenadores municipais.

A ideia de um trabalho horizontal e de ações integradas é excelente, entretanto, a dificuldade de resolução de alguns casos, trazida principalmente pela falta de recursos das redes locais, somado à dificuldade de comunicação das redes locais com os órgãos de garantia de direito, a torna estressante, dada a quantidade de atendimentos fracassados. (PSICÓLOGO - COORDENADOR REGIONAL).

Falta de comunicação extra setoriais, pouco comprometimento entre as partes envolvidas; incompatibilidade de opinião, pouca frequência para discussão de casos graves. (ENFERMEIRA - COORDENAÇÃO LOCAL).

Chama a atenção também o número de coordenadores locais que consideram a comunicação na "Rede" pouco frequente (24,9\%). Algumas respostas nos ajudam a identificar o porquê desta percepção:

(...) a forma como cada um entende para resolver um caso. Às vezes não é todo o grupo que entende a mesma forma de abordagem para um determinado caso. (ENFERMEIRA 1 - COORDENAÇÃO LOCAL).

Isso pode ocorrer pela distância entre a Coordenação Municipal e as coordenações locais. Como já mencionamos na introdução deste trabalho, em raras ocasiões presenciamos a participação dos coordenadores das redes-locais nas reuniões mensais realizadas pela Coordenação Municipal com as regionais. E é justamente nestas reuniões que se discutem os rumos do trabalho, as dificuldades e as estratégias encontradas. A impressão que tivemos é que os coordenadores locais ficam um pouco à margem do processo decisório-político da "Rede de Proteção", tendo em vista que recebem dos coordenadores regionais as informações e as deliberações já definidas anteriormente pelos outros níveis da "Rede".

Segundo Fleury (2005), fortalecer os canais de comunicação nas redes de políticas públicas é uma das estratégias fundamentais para a manutenção do trabalho intersetorial. A estratégia principal utilizada pela "Rede de Proteção" são as reuniões que ocorrem mensalmente em todos os níveis (com exceção das reuniões com os parceiros de fora da Prefeitura, que ocorrem trimestralmente). 
O estabelecimento de canais de comunicação entre os membros da rede parece crucial para o desenvolvimento de valores e objetivos coletivos, permitindo a emergência de uma teia de interdependências e o crescimento da coordenação interorganizacional, que não ameace o equilíbrio da rede. Canais informais baseados em relações pessoais entre pares de indivíduos também costumam ser de grande utilidade no desenvolvimento da coordenação. (p. 85).

Para Migheleto (2001), nas redes de políticas públicas, a comunicação é uma estratégia fundamental para se superar as dificuldades advindas das diferenças (de formação, de linguagem, de percepção).

Conforme nos coloca um dos agentes que ajudou a pensar a proposta de rede intersetorial de enfrentamento à violência contra crianças e adolescentes para o município de Curitiba:

Uma Rede que não se comunica não é Rede. Acho que o sangue da Rede, porque tem que correr, é a comunicação. E é uma comunicação horizontal, não dá para tocar uma Rede com estruturas verticais de mando, de subordinação. Uma Rede é horizontal, mesmo que seja do chefe pro subordinado. Se ela vier como mando, ela se perde na execução, ela tem que vir como cooperação, como troca, como convencimento. Essas relações de companheirismo, e a comunicação circulando, pra mim é o fermento da Rede. E essa coisa do se sentir responsável, então se não está o parceiro, eu pego o problema e resolvo. (...) Então pra mim esses são os elementos: a solidariedade, a cooperação, a comunicação fluindo e a corresponsabilidade são os elementos essenciais de uma Rede. (...) essa comunicação, ela é o sangue da Rede, então se você não está recebendo, não está informando, não está recebendo informação, não está tendo coisa nova, não está sendo estimulado tendência é morrer. (SOCIÓLOGA).

Uma das questões solicitadas no questionário é se existe hierarquia na "Rede de Proteção" tendo em vista que “(...) a hierarquia centralizada é incapaz de responder às necessidades atuais de coordenação flexível de múltiplos atores interdependentes.” (FLEURY, 2005, p. 78).

Houve uma diversidade de respostas: $50 \%$ dos coordenadores municipais, $42,9 \%$ dos regionais e $27,8 \%$ dos locais disseram que não existe hierarquia na "Rede de Proteção".

Não se caracteriza como uma hierarquia (...). Existe a coordenação municipal, coordenação regional, coordenação local das redes, mas não que elas sejam hierárquicas, elas são no sentido horizontal mesmo. (PEDAGOGA 2 - COORDENAÇÃO MUNICIPAL).

No entanto, 33,3\% coordenadores municipais, 28,6\% dos regionais e $19 \%$ dos locais optaram pela categoria mais ou menos, embora as falas das entrevistas esclareçam melhor o que isso significa: 
Não deveria existir..., não deve..., porque a concepção não é essa! A concepção é trabalhar nas localidades, trabalhar cada vez mais as pessoas, unir-se por um objetivo comum, mas a gente vê quem em alguns momentos, até porque nós..., por estarmos nessa instituição pública, em alguns momentos a gente precisa até da hierarquia, no sentido de relatórios, você não tem como, nós não podemos escrever um relatório da Rede de Proteção, nós podemos fazer relatórios das secretarias envolvidas assinadas por suas chefias, que passam pelos setores jurídicos e que daí vai por um único caminho, e até isso, infelizmente, burocratiza, mas também temos que seguir as regras da Instituição. (PEDAGOGA 1 - COORDENAÇÃO MUNICIPAL).

Nesta fala observamos um grande paradoxo entre a concepção teórica de rede e a cotidianidade dos agentes públicos que se vêm obrigados a conviver com a burocracia estatal e a "seguir as regras da Instituição". Isso vem a confirmar nossa hipótese da dificuldade de se operar as políticas públicas através de redes intersetoriais. Pensar agilidade dos encaminhamentos, fluidez nas comunicações, compartilhamento de decisões e poder em espaços públicos rígidos, centralizadores e hierarquizados pode gerar uma angústia muito grande nos agentes que vivem em constante tensão com suas instituições.

Segundo Migheleto (2001), “(...) a nova lógica das redes implica em mudanças no paradigma das teorias organizacionais. E essas mudanças incidem, de forma inexorável, na estrutura de dominação da administração clássica, que encontra na hierarquia um instrumento de poder e controle." (p. 47 grifos nossos).

Dos coordenadores municipais, 16,6\% afirmaram que existe hierarquia na "Rede de Proteção", assim como $19 \%$ dos coordenadores regionais. Os coordenadores locais são os que apresentaram maior percepção da hierarquia no trabalho $(47,8 \%)$, talvez por estarem submetidos a várias chefias (regionais e municipal) e sofrerem com maior intensidade os impactos da estrutura pública, ainda fortemente marcada pelos arranjos institucionais tradicionais.

Sim [existe hierarquia], sabe por quê? Porque é uma rede Institucional, por isso. A verdadeira rede não tem, os teóricos dizem que a rede não tem hierarquia, mas eu estou inserida em uma hierarquia, a minha tomada de decisão, eu não sou livre para a tomada de decisão, eu tenho que me reportar a minha Diretora, e cada um da Rede tem que se reportar, eles, a pessoa da Unidade de Saúde só faz a reunião da Rede com autorização da chefia, teve gente que já teve que pagar hora, no passado. E assim, isso foi muito criticado, porque eu assumi isso de que há uma hierarquia, não porque eu quero mandar, mas é porque eu respondo para trás, então..., existe sim. Existe muita autonomia, mais do que nos outros setores, eu acho que isso foi um avanço, compreende? (MÉDICA 2 COORDENAÇÃO MUNICIPAL).

Observamos na fala uma forte tensão entre a concepção oficial e nativa de "Rede" presente nos seus documentos institucionais (não hierarquizada, comunicativa, ágil, flexível) e os elementos 
presentes no cotidiano profissional (hierarquia, dificuldade de comunicação, especialmente com as chefias, entraves burocráticos, etc.).

(...) falta de apoio das chefias responsáveis. (ENFERMEIRA - COORDENAÇÃO LOCAL).

Existem conflitos pela não participação de algumas instituições e porque não há apoio das chefias. (PEDAGOGA - COORDENAÇÃO LOCAL).

Alguns agentes tiveram a clareza do duplo desafio que foi implementar a "Rede de Proteção" no município de Curitiba buscando "convencer" outros agentes e parceiros a se inserir no trabalho, como o desafio de, em suas próprias instituições, enfrentar a cultura política estabelecida e as relações de poder tradicionalmente instituída dentro de um modelo de Estado autoritário.

Numa perspectiva de rede se pressupõem a substituição do controle hierárquico estatal pelo controle social exercido por segmentos da sociedade civil organizada e pela atuação dos conselhos de políticas públicas. No entanto, a "tentação do poder tradicional" é sempre uma ameaça para novas formas de gestão democráticas e participativas.

(...) já estão acontecendo coisas malucas aqui em Curitiba. Olha só, a gente tem um monitoramento de todas essas gestantes, isso é ótimo, toda a gestante do SUS sabe onde vai ter o seu bebê, certo? Só que monitoramento significa controle, e ai ela é acompanhada no seu pré-natal, e daí ela chega no Hospital, a assistente social avalia o caso, faz um relatório, e o Conselho Tutelar, e por ordem judicial vem e abriga o bebê. (Silêncio) Conclusão: muitas não estão fazendo [pré-natal], muitas! A gente já tem casos de gestantes que não querem fazer o pré-natal e não querem ter o bebê na maternidade. Estão tendo os bebês em casa! (Silêncio) Então, quanto é acompanhamento? Quanto é monitoramento? Quanto é controle, e quando é que nós estamos chegando no admirável mundo novo. (Silêncio) Compreende? Quando você está em um nível central como nós, essa coisa do controle é sempre uma tentação. (...) Então a gente percebe, assim, que a gente infelizmente acaba tendo... porque antes era a Juiza a vigilante, depois o Conselho Tutelar eram os vigilantes e os punidores. Estamos passando uma fase em que nós somos os que vigiam e punem, entre aspas, com a retirada da criança, não sei quem vão ser os próximos. (Risos) Mas é uma pena, porque daí é uma rede de vigilância, na realidade, não uma Rede de Proteção. (MÉDICA 2 - COORDENAÇÃO MUNICIPAL).

Podemos observar uma profunda reflexão do agente sobre a forte ambiguidade que marca o trabalho da "Rede de Proteção". A linha tênue que divide o acompanhamento de gestantes e de crianças em situação de risco, buscando ressarcir direitos humanos violados, também pode representar para as famílias "assistidas" uma invasão do espaço privado, da intimidade e dos seus corpos, se tornando um legítimo instrumento de controle e coerção. 
Ainda como parte do questionário, perguntamos aos coordenadores se a "Rede de Proteção" conseguia atender e acompanhar todos os casos de violência intrafamiliar contra crianças e adolescentes. Os coordenadores regionais responderam que não (47,6\%), enquanto os coordenadores municipais e locais responderam que mais ou menos $(66,6 \%$ e 46,7\%, respectivamente).

O acompanhamento dos casos identificados parece ser o grande desafio da "Rede de Proteção". Em várias reuniões da coordenação municipal com as nove coordenações regionais durante o ano de 2011, este foi o tema pautado com o propósito de elaboração de um documento técnico que orientasse competências, fluxos e formas de acompanhamento e monitoramento das crianças vítimas de violência intrafamiliar.

Não consegue, não consegue [acompanhar os casos], detecta, detecta o caso, é feita a notificação, é iniciado todo o processo, e dai é acompanhado nas Redes Locais. Mas a gente não consegue fazer um acompanhamento mais de perto de todos os casos, é bem difícil. (PROFESSORA - COORDENAÇÃO MUNICIPAL).

Ações ineficazes da Rede de Proteção; volume de trabalho excessivo para os profissionais e, em consequência, não há o efetivo acompanhamento dos casos; falta de objetividade da rede e falta de apoio de órgãos que realmente têm poder de resolução dos casos. (PSICÓLOGA - COORDENAÇÃO LOCAL).

Vários fatores são apontados pelos agentes para explicar porque não ocorre, ou ocorre parcialmente, o acompanhamento dos casos de violência intrafamiliar: a demanda crescente das notificações, a falta de recursos humanos suficientes nas instituições públicas para acompanhar as famílias, além das características específicas deste tipo de violência que, conforme o depoimento que segue, muitas vezes, são marcadas por ciclos, ora de estabilidade, ora de crises.

Pelo menos na sua grande maioria são acompanhados, não solucionados, porque solução imediata sempre seria utopia, mas acompanhados eu acho que a gente consegue. Às vezes que ele fica um pouquinho parado, porque vem outro, uma demanda muito maior, depois você retoma para aqueles casos, e assim, porque eu acredito que rede, os casos de rede, eles não são casos que começam e terminam. Eles são casos cíclicos, de repente ele está estabilizado, dali a dois, três anos, de repente ele retorna, porque claro, a criança, o adolescente, ele tem determinada família, aquela família tem dificuldades, por mais que se invista na família, que se tente, são pessoas, pessoas são, tem formação, tem cultura diferente, tem maneiras de ver diferente... então é isso. (Silêncio) (PEDAGOGA 1 COORDENAÇÃO MUNICIPAL). 
Como podemos observar nas falas, há uma grande angústia por parte dos agentes sobre o que fazer com os casos que são notificados, depois do atendimento emergencial, caracterizando uma das consequências do que Nogueira (2004) chama de "sofrimento institucional":

(...) no contexto histórico atual o campo das organizações em que se entrecruzam tantas novidades e modificações, o campo das organizações mergulhou numa espécie de "estágio de sofrimento", um mal-estar que incomoda e se impõe. Nada funciona muito bem nas organizações, nada satisfaz, nada parece ter força o suficiente para alterar o rumo das coisas, como se a vida e a história estivessem paradas no tempo. No entanto, tudo se move freneticamente. (...) como reação, sobem as taxas de angústia e ansiedade, aumenta a inquietação e tendem a disseminar atitudes de rebeldia, de ceticismo e de niilismo, muitas vezes retóricas e quase sempre impotentes para produzir consensos ativos, contratendências consistentes ou mudanças efetivas no cotidiano organizacional. (NOGUEIRA, 2004, p. 196 grifos nossos).

A partir do momento que se dá visibilidade às demandas sociais, que se cria uma expectativa de resolutividade das situações de violência presenciadas pela comunidade, estima-se que as crianças em situação de vulnerabilidade pela violência sejam atendidas e as famílias acompanhadas para se evitar a reincidência dos casos.

No entanto, a criação da "Rede de Proteção" não garante a infraestrutura necessária das políticas públicas do município para atender todos os casos recebidos, pelo contrário, ela evidencia as falhas no sistema público.

Nós pagamos o preço de estarmos constantemente demonstrando a verdade, não a verdade absoluta, mas a verdade no que diz respeito da falha do serviço. (Silêncio).. é o Posto de Saúde que não tem médico, a professora que perdeu a paciência, a assistente social que não visualizou tudo. E daí a gente tem que entender que o Gestor também tem o primeiro problema do gestor, óbvio, é o financeiro, é o recurso que ele tem. (Silêncio) $O$ trabalho, o serviço público, ele é do tamanho do orçamento. (Silêncio). (...) Então, eu me sinto muito naquela posição assim, do equilibrista, de que eu tenho vários pratos, eu tenho assim, mesmo que a minha coordenação não exista de fato, mas alguém fez uma aposta de que eu iria dar conta, então eu estou girando o prato do Gestor, da necessidade do bebê,, da criança, do Conselho Tutelar que, não adianta eu reclamar do Conselho Tutelar, a Conselheira não me atende, porque ela está atendendo outros casos, óbvio não é? (MÉDICA 2 - COORDENAÇÃO MUNICIPAL).

A fala da coordenadora municipal expressa o quanto é difícil, dentro de uma estrutura burocrática, hierarquizada, onde existem diversos agentes e interesses em jogo, administrar os conflitos e ainda buscar dar conta da totalidade da "vida' das pessoas. A metáfora do equilibrista mostra que você pode girar muitos pratos ao mesmo tempo, mas por um determinado período. Não 
sendo possível permanecer nesta situação de tensão por muito tempo, sem que os pratos caiam, se quebrem e, que as frustrações apareçam.

“O sofrimento organizacional não é mais que um subproduto do mal-estar geral em que se parece viver. Não anuncia a morte ou o caos inevitável, mas convulsiona a vida cotidiana, as consciências individuais e as culturas organizacionais." (NOGUEIRA, 2004, p. 196). E administrar este sofrimento parece ser o grande desafio do gestor das redes de políticas públicas.

Também perguntamos aos coordenadores se a forma como a "Rede de Proteção" está organizada (objetivos, atividades, organograma, coordenações, fluxograma, etc.) favorece o trabalho de enfrentamento da violência intrafamiliar contra crianças e adolescentes.

Observamos diferenças significativas na percepção dos agentes envolvidos nos diferentes níveis de atuação da "Rede". Enquanto os coordenadores municipais foram unânimes na resposta $\operatorname{sim}(100 \%), 57,1 \%$ dos coordenadores regionais e $51 \%$ dos locais concordam que a organização atual da "Rede" ajuda no enfrentamento da violência. No entanto, 38,1\% dos coordenadores regionais e $42,2 \%$ dos locais avaliam que a organização ajuda parcialmente no cumprimento dos objetivos da "Rede de Proteção".

Novamente observamos uma grande distância entre a percepção dos agentes que se encontram nas instâncias que planejam e nas que executam as ações da "Rede de Proteção" , o que pode gerar uma série de conflitos internos no trabalho realizado.

Muitos desafios são enfrentados pelos agentes que compartilham desta experiência no município de Curitiba e pela coordenação geral da "Rede de Proteção", devido à permanência de estruturas organizacionais tradicionais nos serviços públicos, pela insuficiência de programas para atender e acompanhar toda a demanda recebida pela "Rede de Proteção" e pela diversidade de agentes (públicos e privados) pactuando fluxos de atendimento e encaminhamentos a partir de formas de compreensão heterogêneas sobre as problemáticas vivenciadas.

A rotatividade dos agentes nos serviços da "Rede" é um elemento dificultador que faz com que sejam necessárias capacitações permanentes para se criar uma cultura intersetorial nas equipes destinadas a trabalhar com crianças e adolescentes, e para que se percebam como parte integrante desta nova forma de fazer política pública.

Segundo Inojoza (2001), para atuar em rede intersetorial é necessário uma: 
compreensão da diversidade e, com certeza, na questão da comunicação. [...] e não se trata de desprezar ou de ignorar as disciplinas, mas de promover uma comunicação verdadeira entre elas, (INOJOZA, 2001, p. 106 grifos nossos).

Estas mudanças vêm ocorrendo ao longo dos dez anos de trabalho da "Rede de Proteção", no entanto, trata-se de um processo não consolidado, nem homogêneo, marcado por tensões permanentes entre os agentes das diferentes políticas, entre os agentes e suas instituições que, muitas vezes, possuem interesses e objetivos antagônicos, e mesmo entre as instituições envolvidas com este trabalho.

\section{CONSIDERAÇÕES FINAIS}

A "Rede de Proteção" foi criada em Curitiba a partir de uma grande mobilização provocada por agentes públicos, e que contou com uma significativa participação de instituições da sociedade civil na estruturação de um programa intersetorial que desafiou as bases nas quais, até então, as políticas sociais vinham se desenvolvendo no município. A partir de sua institucionalização pela gestão municipal, a "Rede" assumiu novas características ligadas à administração pública tradicional (hierarquia, burocracia, etc.). No entanto, coexistem na atualidade elementos da proposta que originou esta experiência coletiva (cooperação, comunicação ágil, discussão conjunta, etc.), o que gera uma permanente tensão entre a proposta original de "Rede" (presente no imaginário de alguns parceiros e dos profissionais que atuaram na sua construção) e a configuração que se formou a partir da "incorporação" do Programa intersetorial pelo governo municipal.

Vários fatores apontados pelos agentes envolvidos com este trabalho denunciam a ausência de infraestrutura tanto das políticas públicas municipais como estaduais no que diz respeito à escassez de recursos humanos para o atendimento e acompanhamento das vítimas, o despreparo dos agentes, especialmente das delegacias, assim como a dificuldade de comunicação entre as instituições judiciais, o que retrata quão complexo é proteger as vítimas de violência e responsabilizar os agressores.

Pudemos observar a diversidade de agentes envolvidos com o enfrentamento à violência contra crianças e adolescentes e a complexidade das situações vivenciadas por estes nos diferentes 
campos sócio-ocupacionais, o que demonstra uma especialização cada vez maior do trabalho na sociedade contemporânea e a necessidade de integração das instituições em busca do atendimento à população infanto-juvenil.

Como vimos no decorrer da pesquisa, apenas o trabalho da "Rede de Proteção" (entendida enquanto um programa municipal de atendimento e não como rede no sentido sociológico) não é suficiente para garantir o ressarcimento dos direitos de crianças e adolescentes vítimas de violência, nem mesmo para protegê-los de forma imediata.

Frente as tensões explicitadas pelos agentes durante o trabalho de campo é necessário ainda problematizar a relação entre o conceito que os agentes possuem sobre "rede", que é constantemente reforçado pela administração pública municipal, como se trabalhar em rede dependesse apenas da "boa vontade" e da dedicação dos agentes, sem levar em conta as "estruturas estruturadas" (BOURDIEU, 2000) que produzem as condições onde as práticas sociais se desenvolvem.

\section{REFERÊNCIAS}

BOURDIEU, P. Esboço de uma teoria da prática. Precedido de três estudos de Etnologia Cabila. Oeiras: Celtas, 2000.

CURITIBA. Prefeitura Municipal. Manual de Atendimento da Rede de Proteção à Criança e ao Adolescente em Situação de Risco para a Violência. Curitiba, 2002.

.Protocolo da Rede de Proteção à Criança e ao Adolescente em Situação de Risco para a Violência. 2. ed. Curitiba, 2008.

Atendimento psicossocial e psicológico de crianças e adolescentes com suspeita ou confirmação de abuso sexual: papel das Redes Locais. Informação Técnica, Curitiba, n. 11, 2011.

FLEURY, S. Redes de políticas: novos desafios para a gestão pública. Revista Administração em Diálogo, São Paulo, n. 7, p. 77-89, 2005.

INOJOZA, R. M. Redes de Compromisso Social. Revista de Administração Pública, Rio de Janeiro, v. 33, n. 5 , p. $115-141$, set./out. 1999.

Sinergia em políticas e serviços públicos: desenvolvimento social com intersetorialidade. Cadernos FUNDAP, São Paulo, n. 22, p. 102-110, 2001.

JUNQUEIRA, L. A. P. A gestão intersetorial das políticas sociais e o terceiro setor. Saúde e Sociedade, São Paulo, v.13, n.1, p. 25-36, jan./abr. 2004. 
MiGHELETO, D. C. R. Organizações em Rede. 2001, 96 f. Dissertação (Mestrado em Administração Pública), Fundação Getúlio Vargas, Rio de Janeiro, 2001.

OLIVEIRA, V. L. A. et al. Redes de Proteção: novo paradigma de atuação - experiência de Curitiba. In: BRASIL. Ministério da Saúde. Violência faz mal à saúde. Brasília, 2004. p. 143-150.

\title{
Weaving the Protection Network for Children and Adolescents at Risk for Violence in the Municipality of Curitiba / PR
}

\begin{abstract}
The Network for the Protection of Children and adolescents in situation of Risk of Violence in Curitiba / PR, is an intersectoral program created to articulate actions to combat violence in the context of educational public policies, health and social care and to maintain a partnership with several non-governmental organizations that work in the protection of the youth population. In this research we attempted to examine the institutional design of the Network and the tensions that were present in this interaction that brings intersectoral, interdisciplinarity and a methodology of public policies network, both in the case to the conflicts of agents with each other, as the agents with their institutions and the institutions involved in combating violence. The network is an operational strategy of a new form of management of public policies to confront the violence against children and adolescents. It should facilitate the coordination of intersectoral actions, from the conception of a service policy preconized by the Statute of Children and Adolescents, which creates a System of Guarantees of the Rights. However, by the nature of informality, flexibility, agility and centerlessness, operates with difficulty in the public sector, given the permanence of an organizational culture of policies historically marked by hierarchy, sectorization and centralization of the power of decisions. The study identifies the key challenges for the development of intersectoral public actions and concludes that the interdependent relationship between agents and institutions participating in the Protection Network, while it potentiates the actions of combating violence, also generates a constant tension between the institutions and professionals working in the area.
\end{abstract}

KEY-WORDS: Child and adolescent. Family violence.Protection network 